\title{
Dynamics of bacterial communities in a river water treatment wetland
}

\author{
Yong Liu ${ }^{1} \cdot$ Tianli Tong ${ }^{2} \cdot$ Bingxin $\mathrm{Li}^{2} \cdot$ Shuguang Xie ${ }^{2}$
}

Received: 31 October 2018 / Accepted: 19 February 2019 / Published online: 27 February 2019

(C) Università degli studi di Milano 2019

\begin{abstract}
Bacteria play important roles in the removal of inorganic and organic pollutants in constructed wetlands (CWs) used for surface water treatment, however, the environmental variables driving the change of bacterial community remain poorly understood. The present work explored seasonal and spatial dynamics of bacterial communities in a large $\mathrm{CW}$ used for river water treatment and the associated environmental variables. Quantitative PCR assay and high-throughput sequencing analysis were used to determine the abundance, richness, diversity, and structure of wetland bacterial community. Bacterial abundance was correlated to nitrite and temperature, while bacterial diversity could be influenced by $\mathrm{pH}$ as well as carbon, nitrogen, and phosphorus. Bacterial community structure might be shaped by nitrogen and phosphorus. A considerable difference in bacterial community composition existed between wetland soils and sediments. Proteobacteria (accounting for 33-60\%) was the largest bacterial phylum, and Chloroflexi (5-24\%) was also abundant. The abundance, richness, diversity, and composition of the bacterial community were influenced by wetland plant type and wetland trophic status.
\end{abstract}

Keywords Microbial community $\cdot$ Proteobacteria $\cdot$ Surface water $\cdot$ Constructed wetland $\cdot$ Vegetation type

\section{Introduction}

Constructed wetlands (CWs), especially free water surface flow CWs (FWSF-CWs), have been widely applied to ameliorate the quality of polluted surface water (Ibekwe et al. 2007; Ligi et al. 2014; Dzakpasu et al. 2015; Fang et al. 2016; Zheng et al. 2016), because of their merits of cost-effectiveness, eco-environmental friendliness, and easy management. Microorganisms play a crucial role in the removal of inorganic and organic pollutants in CWs (Chang et al. 2015; Guan et al. 2015; He et al. 2016). Various bacterial assemblages can coexist in CWs treating surface water (Ligi

Electronic supplementary material The online version of this article (https://doi.org/10.1007/s13213-019-01454-x) contains supplementary material, which is available to authorized users.

Shuguang Xie

xiesg@pku.edu.cn

1 Key Laboratory of Water and Sediment Sciences (Ministry of Education), College of Environmental Sciences and Engineering, Peking University, Beijing 100871, China

2 State Key Joint Laboratory of Environmental Simulation and Pollution Control, College of Environmental Sciences and Engineering, Peking University, Beijing 100871, China et al. 2014; Guan et al. 2015; He et al. 2016; Long et al. 2016a, b; Cao et al. 2017), and they can have different responses to the change of environmental variables. A few previous studies have documented site-related changes of bacterial community abundance, diversity, and structure in FWSF-CWs used for surface water treatment (Ibekwe et al. 2007; Ligi et al. 2014; Tu et al. 2014; Zhi et al. 2015; Cao et al. 2017), while much less attention has been paid to the temporal or seasonal change of bacterial community (Ibekwe et al. 2007). To date, the environmental variables influencing the bacterial community in FWSF-CW used for surface water treatment remain poorly understood. Ligi et al. (2014) suggested that soil bacterial community structure in a FWSF-CW used for river water treatment might be regulated by multiple factors, such as $\mathrm{pH}$, ammonia, nitrate, and total carbon. Moreover, it has been well-documented that plant type can have profound impacts on bacterial populations in natural wetlands ( $\mathrm{Yu}$ et al. 2012; Lee et al. 2015; Lee and Kang 2016; Rietl et al. 2016) and a vertical-flow $\mathrm{CW}$ (VF-CW) used for surface water treatment (Long et al. 2016a). However, information about the influence of plant type on bacterial community in FWSF-CW used for surface water treatment is still lacking, although a previous study indicated that plant density could affect bacterial diversity in a FWSF-CW used for river water treatment (Ibekwe et al. 2007). 
Previous studies on bacterial diversity and community composition in FWSF-CWs used for surface water treatment mainly relied on denaturing gradient gel electrophoresis (DGGE) (Ibekwe et al. 2007; Tu et al. 2014; Zhi et al. 2015), while high-throughput sequencing technology can provide an opportunity to systematically investigate wetland bacterial community and the associated environmental variables (Ligi et al. 2014). Therefore, the overall objective of the current study was to investigate seasonal and spatial dynamics of the bacterial community in a FWSF-CW used for river water treatment and the associated environmental variables. The abundance, diversity, and composition of wetland bacterial community were determined using quantitative PCR assay and Illumina MiSeq high-throughput sequencing.

\section{Materials and methods}

\section{Study site and sampling}

Triplicate wetland sediment samples (at sites A-F) and soil samples (at sites $\mathrm{G}$ and $\mathrm{H})\left(0-10 \mathrm{~cm}\right.$ depth) $\left(25^{\circ} 56^{\prime} 42^{\prime \prime}-25^{\circ}\right.$ $57^{\prime} 11^{\prime \prime} \mathrm{N}, 100^{\circ} 6^{\prime} 0^{\prime \prime}-100^{\circ} 6^{\prime} 9^{\prime \prime} \mathrm{E}$ ) (Fig. S1) (Li et al. 2017) were collected from a FWSF-CW used for river water treatment (with the surface area of nearly $0.47 \mathrm{~km}^{2}$ and the average water depth of $1.5 \mathrm{~m}$ ) in spring (March), summer (August), and winter (December) in 2016. The FWSF-CW was located in subtropical Dali City (southwest China), with annual average air temperature of $15.7^{\circ} \mathrm{C}$ and annual average precipitation of $1000 \mathrm{~mm}$ (Li et al. 2017). Site G (highland in wetland center, vegetated with alfalfa) and site $\mathrm{H}$ (wetland edge, vegetated with cattail) were flooded only during summer and autumn (wet seasons), while other sampling sites (A-F) were flooded during both wet and dry seasons and were vegetated mainly with water hyacinth, reed, watermilfoil, penny grass, duckweed, and water lily, respectively. In accordance with our previous study ( $\mathrm{Li}$ et al. 2017), the collected sediment/soil samples were coded as $\mathrm{A}-\mathrm{H}$, corresponding to the sampling site, and SP, SU, or WI, corresponding to the sampling period (spring, summer, or winter, respectively). The sample at site B during winter was not collected because of inaccessibility; thus, no sample was coded "BWI." Sediment/soil physicochemical parameters, such as $\mathrm{pH}$, oxidation, and reduction potential (ORP), temperature, total organic carbon (TOC), total phosphorus (TP), total nitrogen (TN), the ratio of TOC to $\mathrm{TN}(\mathrm{C} / \mathrm{N})$, nitrate nitrogen $\left(\mathrm{NO}_{3}{ }^{-}-\mathrm{N}\right)$, ammonia nitrogen $\left(\mathrm{NH}_{4}{ }^{+}-\mathrm{N}\right)$, and nitrite nitrogen $\left(\mathrm{NO}_{2}{ }^{-}-\mathrm{N}\right)$ were described in our previous study (Li et al. 2017).

\section{Quantitative PCR analysis}

Wetland sediment/soil genomic DNA was extracted using Powersoil DNA extraction kit (MO BIO Laboratories,
Carlsbad, California, USA). The DNA quality was assessed using $1.2 \%$ agarose gel electrophoresis and the amount of DNA was determined using a NanoDrop 2000 Spectrophotometer (Thermo Fisher Scientific, USA). In the present study, the number of bacterial 16S rRNA gene was quantified by quantitative PCR with primer pairs $341 \mathrm{~F}\left(5^{\prime}\right.$ CCTACGGGAGGCAGCAG-3')/534R (5' - ATTA CCGCGGCTGCTGGCA-3') (Jung et al. 2011), using the amplification conditions: $10 \mathrm{~min}$ at $95^{\circ} \mathrm{C} ; 40$ cycles of $95^{\circ} \mathrm{C}$ for $30 \mathrm{~s}, 55^{\circ} \mathrm{C}$ for $30 \mathrm{~s}$, followed by $72{ }^{\circ} \mathrm{C}$ for $30 \mathrm{~s}$. A plasmid standard containing the targeted gene from Escherichia coli was used to set up standard curve, with the amplification efficiency of $97 \%$ and the amplification coefficient of 0.999 .

\section{High-throughput sequencing analysis}

For construction of PCR amplicon libraries, wetland sediment/soil DNA was amplified with bacterial primers 515F (5'-GTGCCAGCMGCCGCGG-3')/R907 (5'-CCGT CAATTCMTTTRAGTTT-3') (Xiong et al. 2012), following the same amplification conditions described in the literature (Wang et al. 2015). PCR products were purified using the TIANquick Mini Purification Kit (Tiangen Biotech (Beijing) Co., LTD, Beijing, China). The purified amplicons from triplicate wetland sediment/soil samples were pooled in equal amounts and submitted for Illumina MiSeq sequencing at Shanghai Majorbio Bio-pharm Technology Co., Ltd. The raw bacterial reads had been deposited in Sequence Read Archive database with the accession number SRP103270. Pairs of reads were merged using FLASH and low-quality composite reads were removed using QIIME (Caporaso et al. 2010). Chimeric bacterial sequences were screened and then discarded with UCHIME (Edgar et al. 2011). Bacterial sequences (with a $3 \%$ dissimilarity cutoff) were assigned into operational taxonomic units (OTUs) and community $\alpha$-diversity indices (Chaol richness estimator and Shannon diversity index) were generated using UPARSE (Edgar 2013).

To identify the difference of bacterial community composition among various sediment/soil samples, weighted UniFrac distance was calculated and UniFrac-based hierarchical clustering was performed using the $R$ software (version i386, 3.3.2) (https://www.r-project.org/). In addition, the taxonomic identities of bacterial sequences were assigned using the Silva rRNA database (Quast et al. 2013).

\section{Statistical analysis}

The difference in bacterial $16 \mathrm{~S}$ rRNA gene number was checked at a 5\% significance level with one-way analysis of variance (ANOVA). The possible relationships between sediment/soil physicochemical variables and bacterial abundance, richness and diversity were examined with Spearman's rank correlation analysis (using the software SPSS 20.0 (IBM, 
Armonk, NY, USA)). Redundancy analysis (RDA) with Monte Carlo tests was performed to determine the bacteriaenvironment relationships using the software CANOCO 4.5 (Microcomputer Power, Ithaca, NY, USA). The sequence number in each major OTU (with a cutoff of 50 bacterial sequences) was assigned as species input, whereas physicochemical parameters were applied as environmental input (Zhang et al. 2015a).

\section{Results}

\section{Bacterial community abundance}

The density of bacterial 16S rRNA gene in wetland sediments varied from $3.19 \times 10^{10}$ to $1.35 \times 10^{11}$ copies per gram dry sediment, while soils contained $1.71 \times 10^{10}-1.08 \times 10^{11}$ bacterial 16S rRNA gene copies per gram dry soil (Fig. 1). At each sampling site (except site B), a significant difference in bacterial community size was observed among the samples collected during three different seasons $(P<0.05)$, indicating an evident seasonal change of bacterial abundance in the studied river water treatment $\mathrm{CW}$. Moreover, the season-related change pattern of wetland bacterial abundance appeared to be site-specific. An evident change of bacterial abundance with sampling site also occurred in the studied wetland. During each season, a significant difference in bacterial abundance could be observed among sediment samples or between soil samples $(P<0.05)$.

\section{Bacterial richness and diversity}

In the present study, sequence number from each wetland sample was normalized to the same sequencing depth (with 17,055 bacterial sequences) in order to compare sediment/soil

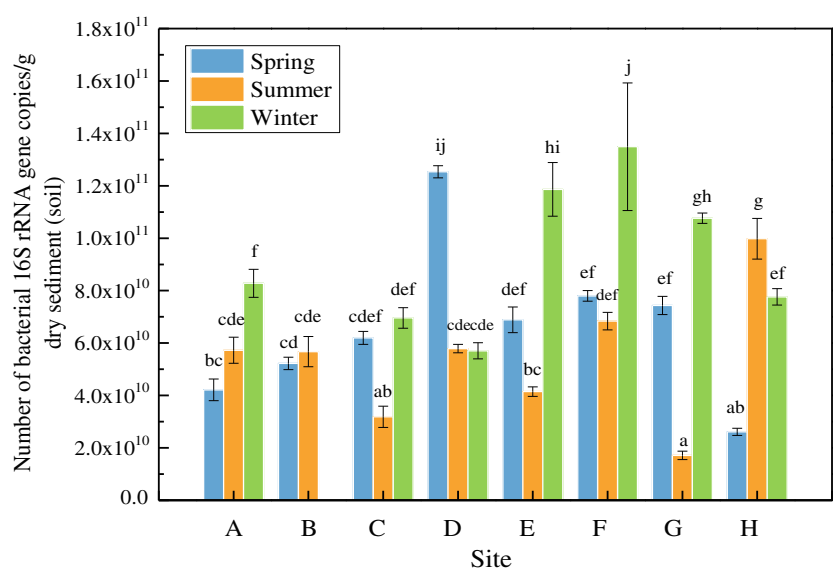

Fig. 1 Bacterial abundance of wetland sediments and soils. Values are the average of triplicate samples. Vertical bars indicate standard deviations. Different letters above the columns display the significant difference in 16S rRNA gene abundance $(P<0.05)$ bacterial community richness and diversity. High Good's coverage estimators ( $\geq 95.9 \%$ ) implied that, in each wetland sediment/soil, most of bacterial OTUs had been captured. Each wetland bacterial library included 1487-3073 OTUs (Fig. 2a). At each sampling site, bacterial OTU number illustrated an evident seasonal change. The season-related change pattern of bacterial OTU number varied among sampling sites. In addition, in the studied wetland, an evident site-related change of bacterial OTU number was also observed during each season.

Wetland sediment/soil bacterial Chao1 richness estimator varied from 1794 to 3643 (Fig. 2b). At each sampling site, wetland bacterial community richness displayed a noticeable seasonal change. The season-related change pattern of wetland bacterial richness was also site-specific. In addition, in the wetland used for river water treatment, a remarkable siterelated variation of bacterial richness existed during each season.

Bacterial Shannon diversity index in river water treatment wetland ranged between 5.16 and 6.96 (Fig. 2c). At each sampling site (except site A), wetland bacterial community diversity displayed a remarkable seasonal change. The season-related change pattern of wetland bacterial diversity depended on sampling site. In the studied $\mathrm{CW}$, bacterial diversity also showed a remarkable variation with sampling site during each season.

\section{Clustering analysis of bacterial communities}

The results of clustering illustrated a considerable site-related shift in bacterial community structure in the studied wetland used for river water treatment (Fig. 3). During each season, wetland soil samples were distantly separated from wetland sediment samples, and sediment samples themselves also showed a clear separation. Moreover, a seasonal shift in bacterial community structure could also be observed in the studied FWSF-CW, depending on the sampling site. At sampling site A, sediment samples collected during three seasons could be clustered together, while at sites $\mathrm{B}, \mathrm{C}, \mathrm{D}, \mathrm{E}$, and F, the sediments collected during summer were distantly separated from the corresponding ones collected during spring and winter. The soil sample collected during winter was more distantly separated from the corresponding ones during spring and summer at site $\mathrm{G}$ than at site $\mathrm{H}$.

\section{Bacterial community composition}

In this study, a total of 14 bacterial phyla were frequently detected in the studied FWSF-CW used for river water treatment, including Proteobacteria, Chloroflexi, Actinobacteria, Acidobacteria, Bacteroidetes, Planctomycetes, Chlorobi, Firmicutes, Nitrospirae, Aminicenantes, Cyanobacteria, Latescibacteria, Gemmatimonadetes, and Spirochaetae 
(a)

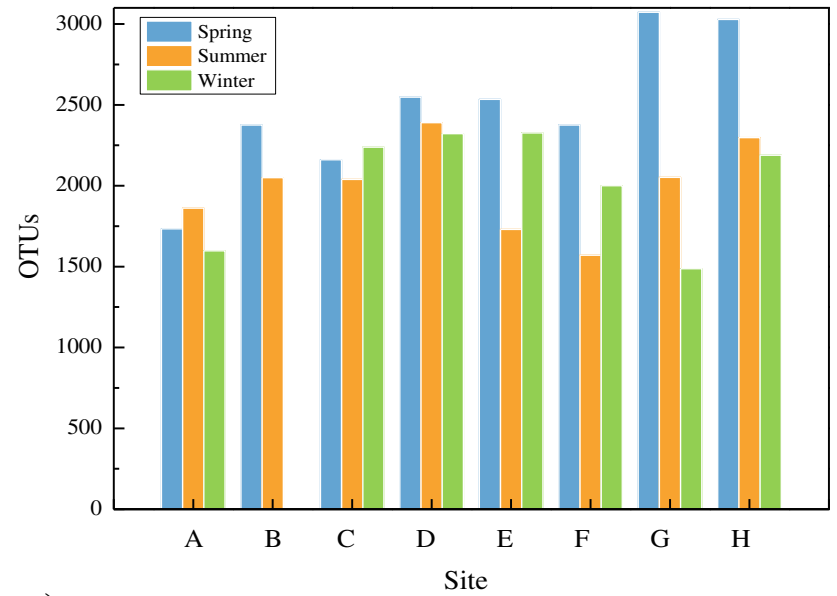

(b)

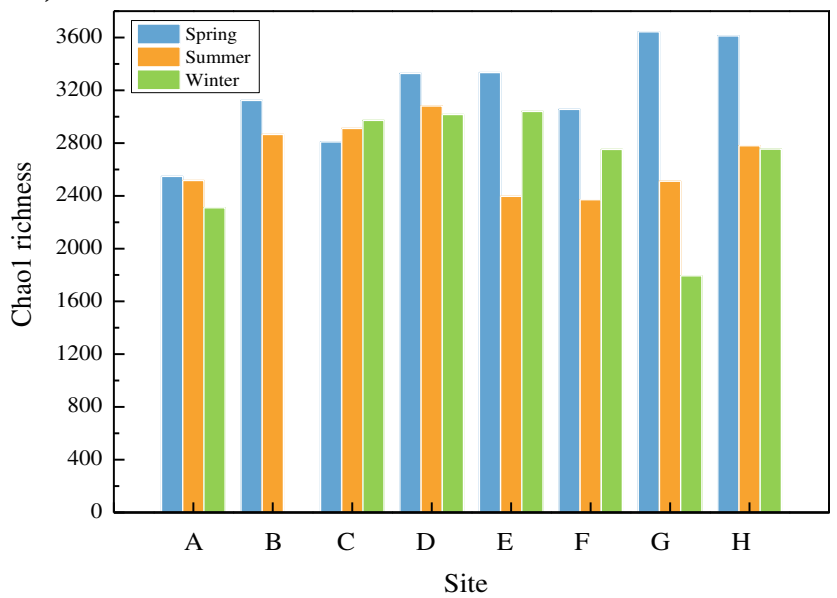

(c)

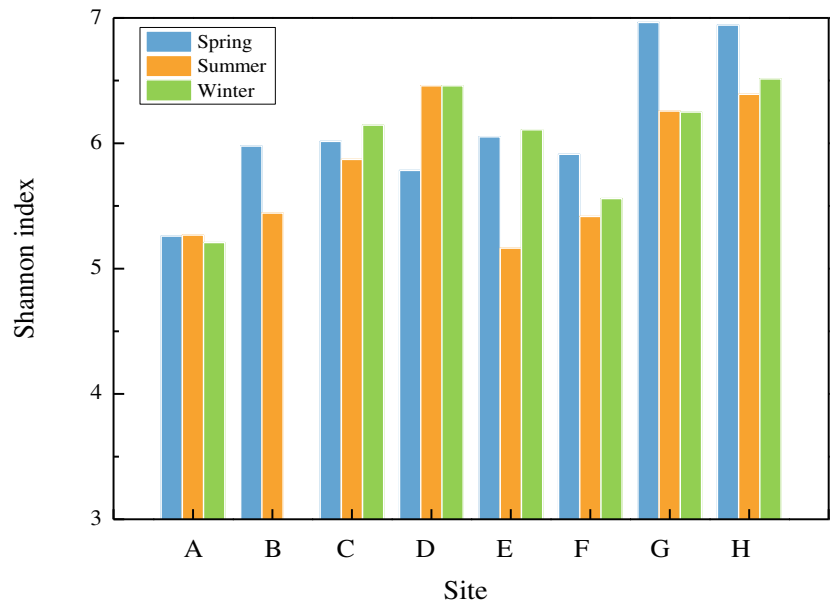

Fig. 2 a Wetland sediment/soil bacterial OTUs, b Chaol estimator, and c Shannon index

(Fig. 4). Proteobacteria was found to be the largest bacterial phylum (accounting for 33-60\%) in each wetland sediment/ soil sample. Proteobacterial communities of wetland sediment/soil samples were mainly comprised of Betaproteobacteria, Gammaproteobacteria, and
Deltaproteobacteria, while Alphaproteobacteria was also a major proteobacterial class in wetland soil samples (Fig. S2). The season-related change of proteobacterial proportion was site-specific. Proteobacterial proportion varied slightly at sites $\mathrm{B}, \mathrm{C}$, and $\mathrm{G}$ but considerably at other sampling sites. Moreover, the site-related variation of proteobacterial proportion was obvious in the FWSF-CW. Sediments generally have higher proteobacterial proportion than soils. During each season, proteobacterial proportion also differed evidently in sediment samples.

Chloroflexi (accounting for 5-24\%) was usually the second largest bacterial phylum in wetland samples. The seasonrelated variation of Chloroflexi proportion was also site-specific. Chloroflexi proportion illustrated a slight seasonal change at sites $\mathrm{C}$ and $\mathrm{F}$ but a considerable one at other sites. Moreover, during each season, the $\mathrm{CW}$ displayed a remarkable site-related variation of Chloroflexi proportion.

\section{Influential factors regulating bacterial community}

Spearman's rank correlation analysis showed that wetland sediment/soil bacterial community size was positively correlated to $\mathrm{NO}_{2}{ }^{-} \mathrm{N}$ concentration $(P<0.05)$ but negatively to temperature $(P<0.05)$ (Table 1$)$. Bacterial diversity showed positive correlations to $\mathrm{pH}, \mathrm{TN}, \mathrm{TOC}, \mathrm{C} / \mathrm{N}$, and $\mathrm{TP}(P<0.05$ or $P<0.01)$ but was negatively correlated to $\mathrm{NH}_{4}{ }^{+}-\mathrm{N}$ $(P<0.01)$. Moreover, proteobacterial proportion illustrated significant correlations to $\mathrm{NH}_{4}{ }^{+}-\mathrm{N}, \mathrm{TOC}$, and $\mathrm{C} / \mathrm{N}(P<0.05$ or $P<0.01)$. However, no significant correlation was observed between the determined wetland physicochemical parameters and bacterial richness and Chloroflexi proportion $(P>0.05)$.

The determined $\mathrm{CW}$ environmental variables in the first two RDA dimensions respectively accounted for 65.7 and $7.6 \%$ of the variance for bacterial OTU composition (Fig. 5). A number of sediment/soil physicochemical parameters, including TP $(F=12.786, P=0.001,999$ permutations), TN $(F=3.908, P=0.001,999$ permutations $), \mathrm{NH}_{4}{ }^{+}-\mathrm{N}(F=$ 2.043, $P=0.009,999$ permutations $), \mathrm{NO}_{3}{ }^{-} \mathrm{N}(F=1.738$, $P=0.031,999$ permutations $)$, and $\mathrm{NO}_{2}{ }^{-} \mathrm{N}(F=1.675, P=$ $0.046,999$ permutations), significantly contributed to the wetland Bacteria-environment relationship.

\section{Discussion}

\section{Temporal and spatial variations of wetland bacterial abundance}

Two previous studies have reported a considerable spatial heterogeneity of sediment or soil bacterial abundance in FWSFCWs treating river water (Ligi et al. 2014; Zhi et al. 2015), yet information about the temporal change of bacterial abundance 
Fig. 3 Clustering of wetland bacterial communities based on weighted UniFrac

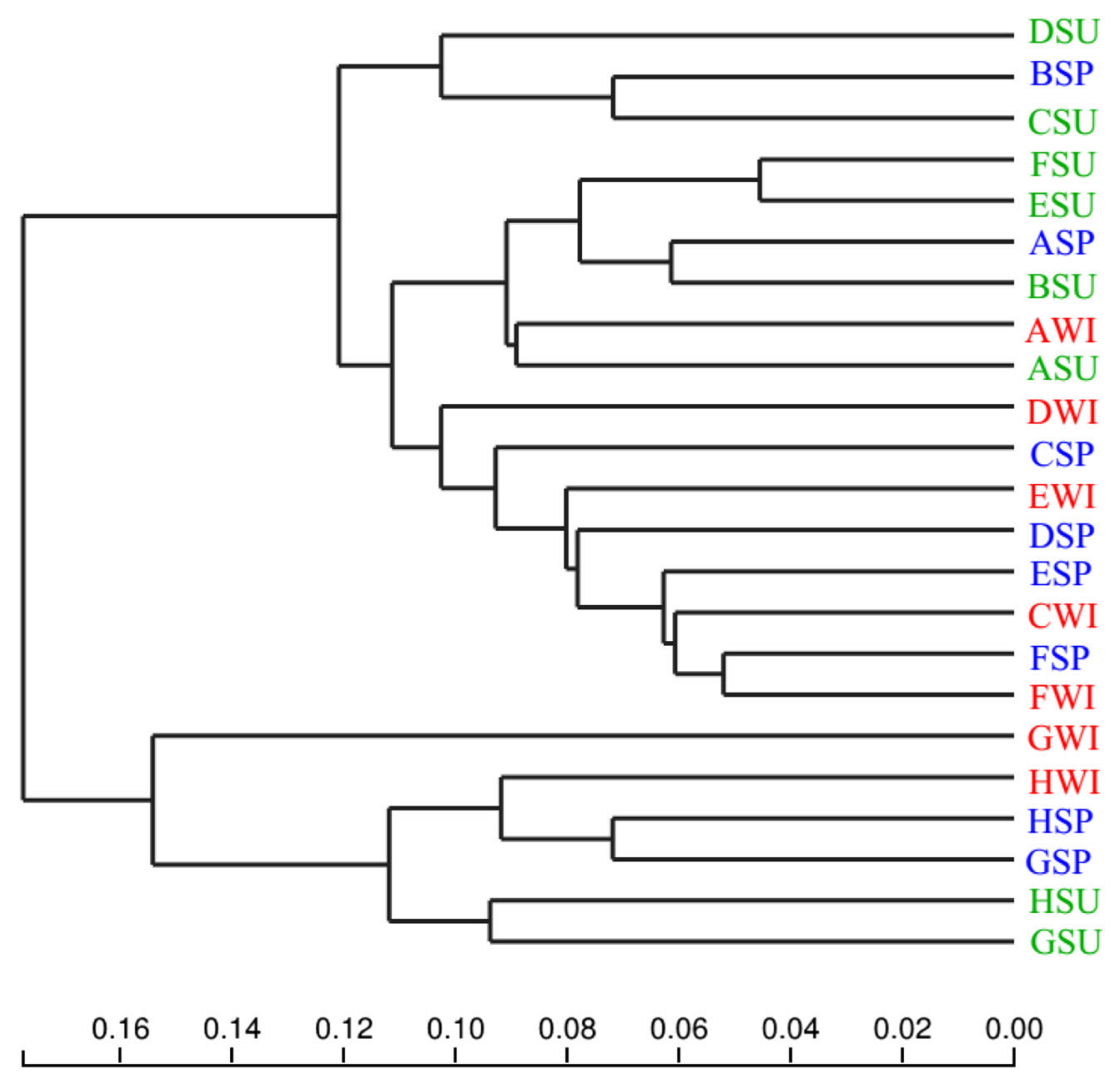

in FWSF-CW used for surface water treatment is still lacking. In the current study, bacterial community size in the FWSF$\mathrm{CW}$ used for river water treatment varied among seasons and sampling sites, ranging from $1.71 \times 10^{10}$ to $1.35 \times 10^{11} 16 \mathrm{~S}$ rRNA gene copies per gram dry sediment/soil, much higher than the reported values in other FWSF-CWs used for surface water treatment (Ligi et al. 2014; Zhi et al. 2015). The bacterial community size in the studied FWSF-CW was also much higher than the archaeal abundance $\left(3.37 \times 10^{8}\right.$ to $3.59 \times 10^{9}$ archaeal 16S rRNA gene copies per gram dry sediment/soil) (Li et al. 2017), suggesting more important biochemical roles of bacteria in the wetland. Moreover, the season-related change pattern of wetland bacterial abundance was found to differ at sites with different plant species. These results suggested that plant type might influence bacterial abundance in the FWSF-CW. The potential influence of plant type on bacterial abundance has also been reported in natural wetlands (Lee and Kang 2016) and CWs treating industrial wastewater (Calheiros et al. 2010) or synthetic wastewater (Zhang et al. 2015b; Liu et al. 2016). In addition, Long et al. (2016a) also suggested that plant type might be a key determinant to bacterial abundance in a VF-CW used for river water treatment.

So far, the links between environmental variables and bacterial abundance in CW used for surface water treatment remain essentially unclear. In this study, Spearman's rank correlation analysis suggested that sediment/soil bacterial abundance in surface water treatment FWSF-CW might be negatively influenced by temperature rise. At half of the eight studied sampling sites, the sediment/soil samples collected during summer showed lower bacterial abundance than the corresponding ones collected during spring and winter. At another two sites, bacterial density in sediment samples collected during spring and winter also outnumbered the corresponding one collected during summer. In contrast, a previous study indicated that bacterial abundance was much higher in summer than in winter in a microcosm CW used for wastewater treatment (Wang et al. 2016). Moreover, there was a paucity of knowledge on the relationship between wetland bacterial abundance and nitrite concentration. In this study, Spearman's rank correlation analysis suggested the positive influence of nitrite concentration on bacterial abundance in a FWSF-CW used for surface water treatment. Nutrients were usually a key factor regulating bacterial abundance in freshwater sediment (Dai et al. 2016; Liu et al. 2015; Zhang et al. 2015a).

\section{Temporal and spatial variations of wetland bacterial richness and diversity}

A few previous studies have displayed evident spatial changes of sediment/soil bacterial richness and diversity in FWSFCWs used for surface water treatment (Ibekwe et al. 2007; Ligi et al. 2014; Zhi et al. 2015; Cao et al. 2017), while only an earlier study documented the temporal change of sediment 


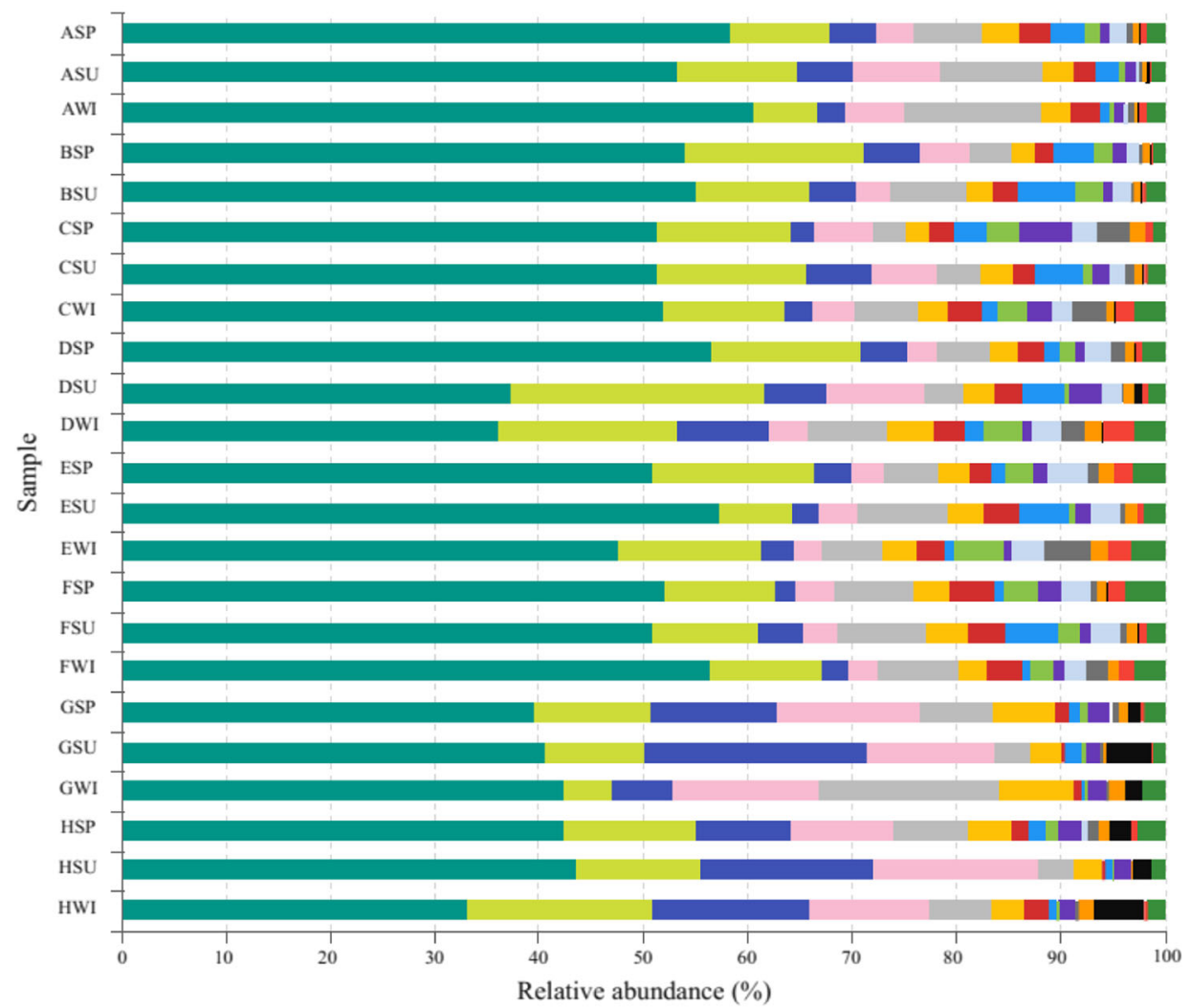

Relative abundance $(\%)$

Fig. 4 Comparison of the quantitative contribution of the sequences affiliated with different bacterial phyla to the total number of sequences from a given wetland sediment/soil sample. Others include the bacterial phyla with the largest relative abundance less than $1 \%$ in each wetland sample

bacterial diversity in a FWSF-CW used for surface water treatment (Ibekwe et al. 2007). Moreover, Ibekwe et al. (2007) also suggested that plant density could influence wetland bacterial diversity. However, these previous studies have not paid attention to the links of wetland vegetation type with bacterial richness and diversity. In addition, wetland bacterial richness and diversity were found to vary among both seasons and sampling sites, in agreement with the result reported in a previous study (Ibekwe et al. 2007). The present study further revealed that the season-related change of bacterial richness and diversity differed at sites with different wetland vegetation species. These results further suggested the potential influence of vegetation type on bacterial richness and diversity in the FWSF-CW. Several previous studies also suggested important roles of vegetation type in determining bacterial richness and diversity in natural wetlands (Yu et al. 2012; Lee et al. 2015; Lee and Kang 2016), and CWs treating industrial wastewater (Calheiros et al. 2010) or synthetic wastewater (Liu et al. 2016; Zhang et al. 2015b), and a VF-CW used for river water treatment (Long et al. 2016a). There has been no report

Table 1 Spearman's rank correlation analysis of wetland sediment/soil environmental factors with the abundance, richness, and diversity of bacterial communities and the relative abundance of Proteobacteria and Chloroflexi organisms

\begin{tabular}{|c|c|c|c|c|c|c|c|c|c|c|}
\hline & $\mathrm{pH}$ & Temperature & ORP & $\mathrm{NH}_{4}{ }^{+}-\mathrm{N}$ & $\mathrm{NO}_{2}^{-}-\mathrm{N}$ & $\begin{array}{l}\mathrm{NO}_{3}{ }^{-}- \\
\mathrm{N}\end{array}$ & $\mathrm{TN}$ & TOC & $\mathrm{C} / \mathrm{N}$ & $\mathrm{TP}$ \\
\hline Abundance & 0.040 & $-0.478^{*}$ & -0.143 & -0.206 & $0.428^{*}$ & 0.246 & 0.061 & -0.031 & -0.291 & -0.200 \\
\hline Chao1 richness & 0.173 & -0.077 & 0.176 & -0.256 & -0.012 & -0.220 & 0.249 & 0.271 & 0.257 & -0.066 \\
\hline Shannon diversity & $0.455^{*}$ & -0.137 & 0.155 & $-0.776^{* *}$ & 0.390 & 0.154 & $0.442^{*}$ & $0.651^{* *}$ & $0.469^{*}$ & $0.435^{*}$ \\
\hline Proteobacteria & -0.377 & 0.008 & -0.088 & $0.642 * *$ & -0.255 & -0.146 & -0.308 & $-0.533^{* * *}$ & $-0.426^{*}$ & -0.321 \\
\hline Chloroflexi & -0.056 & -0.203 & 0.142 & -0.069 & 0.128 & -0.155 & 0.235 & 0.351 & 0.216 & -0.098 \\
\hline
\end{tabular}

*Correlation is significant at the 0.05 level

***Correlation is significant at the 0.01 level 
Fig. 5 RDA ordination plot for the first two principal dimensions of the links between bacterial OTU composition and wetland sediment/soil physicochemical parameters

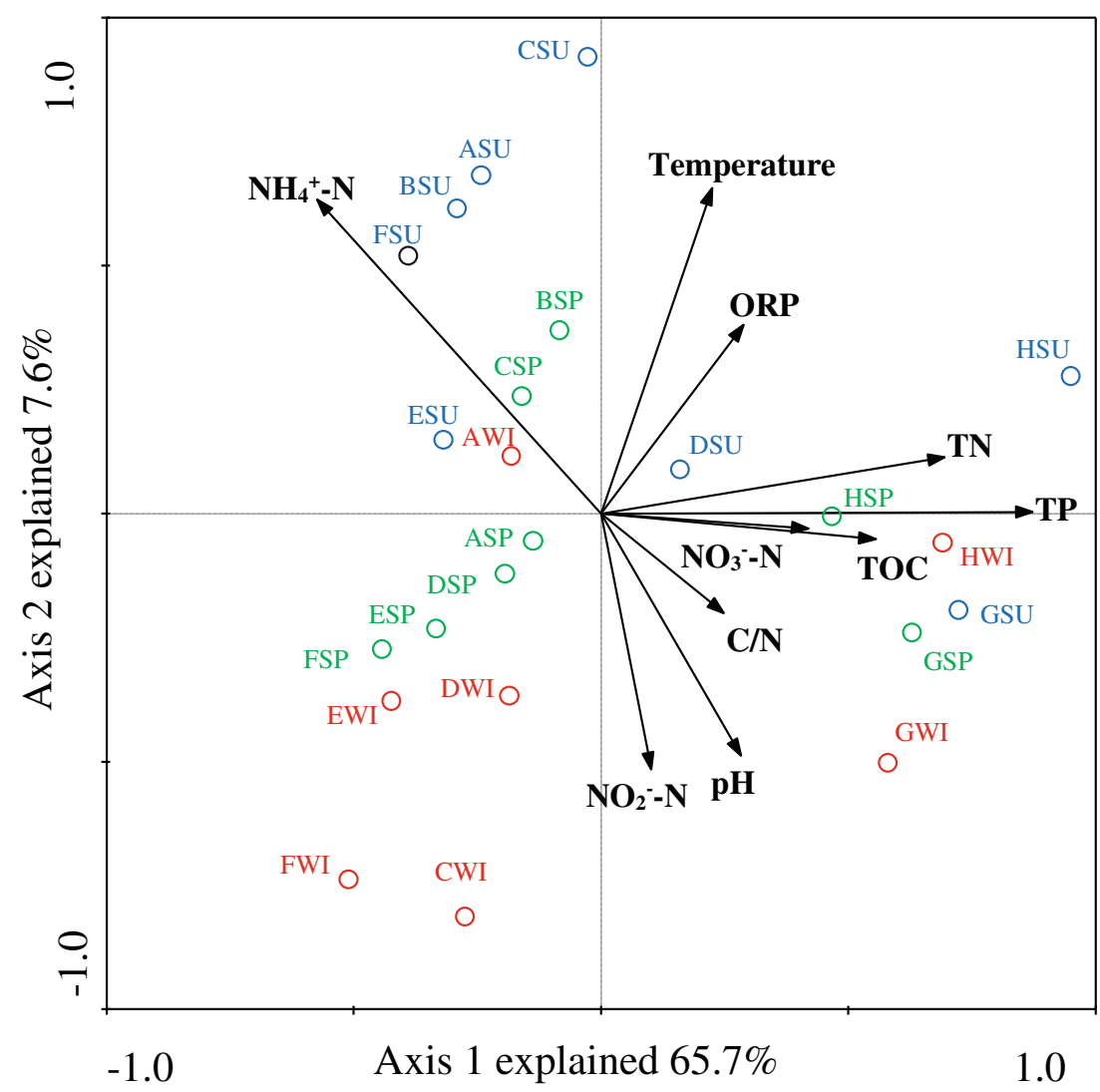

available on the links between environmental variables and sediment/soil bacterial richness and diversity in $\mathrm{CW}$ used for surface water treatment. In this study, no clear correlation of wetland bacterial richness with environmental variables was identified. However, Spearman's rank correlation analysis suggested that bacterial diversity in FWSF-CW used for surface water treatment could be collectively determined by many variables including $\mathrm{pH}, \mathrm{NH}_{4}{ }^{+}-\mathrm{N}, \mathrm{TN}, \mathrm{TOC}, \mathrm{C} / \mathrm{N}$, and TP. The variables associated with the trophic status were also found to be the key determinants of bacterial diversity in freshwater sediment (Dai et al. 2016; Xiong et al. 2015; Yu et al. 2015; Zhang et al. 2015a). Therefore, the wetland trophic status might play an important role in determining wetland bacterial diversity.

\section{Temporal and spatial variations of wetland bacterial community structure}

Two previous studies have indicated an obvious site-related change of sediment/soil bacterial community structure in FWSF-CWs used for surface water treatment (Ligi et al. 2014; Cao et al. 2017), yet no direct information existed on the temporal change of bacterial community structure in FWSF-CW used for surface water treatment. Moreover, the associations of bacterial community structure with plant type in FWSF-CW used for surface water treatment remain unknown, although previous studies suggested that plant type might play an important role in shaping bacterial community structure in natural wetlands (Yu et al. 2012; Lee et al. 2015; Lee and Kang 2016; Rietl et al. 2016), wastewater treatment CWs (Calheiros et al. 2010; Arroyo et al. 2013; Zhang et al. 2015b; Liu et al. 2016), a CW fed with groundwater (Menon et al. 2013), and a VF-CW used for river water treatment (Long et al. 2016a). In this study, the results of both clustering analysis and phylogenetic analysis indicated noticeable seasonal and spatial shifts in bacterial community structure in the studied FWSF-CW, and its season-related change was sitespecific. These results also suggested a potentially important role of vegetation type in shaping FWSF-CW bacterial community structure. In this study, wetland soils and sediments differed greatly in bacterial community structure. A considerable difference in soil microbial community structure was also found between permanently and occasionally flooded areas in a FWSF-CW used for river water treatment (Ligi et al. 2014). So far, little is known about the environmental factors driving bacterial community structure in FWSF-CW used for surface water treatment. In this study, the result of RDA suggested that $\mathrm{NH}_{4}{ }^{+}-\mathrm{N}, \mathrm{NO}_{2}{ }^{-}-\mathrm{N}, \mathrm{NO}_{3}{ }^{-}-\mathrm{N}, \mathrm{TN}$, and TP collectively shaped FWSF-CW bacterial community structure. Ligi et al. (2014) indicated that bacterial community structure in a FWSF-CW used for river water treatment might be regulated by the concentrations of ammonia, nitrate, and total carbon. Therefore, 
the wetland trophic status was likely the determinant of wetland bacterial community structure. Some previous studies have also confirmed the key role of trophic status in shaping freshwater sediment bacterial community structure (Dai et al. 2016; Zhang et al. 2015a).

Microorganisms from phylum Proteobacteria can participate in various biogeochemical processes (Cheng et al. 2014; Liu et al. 2014). A dominance of proteobacterial organisms has been found in both FWSF-CW and VF-CW treating surface water (Ligi et al. 2014; Guan et al. 2015; Zhi et al. 2015; He et al. 2016; Long et al. 2016a, b). In consistency with these previous studies, proteobacterial organisms were also found to be the largest bacterial group (accounting for 33-60\% in bacterial community) in the studied FWSF-CW. The relative abundance of proteobacterial organisms in bacterial community could considerably vary among sampling sites in a FWSF-CW used for surface water treatment (Ligi et al. 2014) or among layer depths in VF-CWs used for surface water treatment (Guan et al. 2015; He et al. 2016). He et al. (2016) also reported an evident temporal variation of proteobacterial proportion in a VF-CW used for surface water treatment. The present study revealed an evident variation of proteobacterial proportion with sampling site in a FWSF-CW used for surface water treatment, and further provided the evidence for the seasonal change of proteobacterial proportion. Moreover, Long et al. (2016a) indicated that the proteobacterial proportion in a VF-CW used for surface water treatment was related to plant type, while the present study further provided the evidence for the influence of plant type on determining proteobacterial proportion in a FWSF-CW used for surface water treatment. To date, the environmental variables driving proteobacterial proportion in FWSF-CW remain unclear. In the current study, proteobacterial proportion in the FWSF-CW was found to be correlated to some variables related to wetland trophic status (e.g., $\mathrm{NH}_{4}{ }^{+}-\mathrm{N}$, TOC, and the $\mathrm{C} / \mathrm{N}$ ratio).

Chloroflexi organisms are ubiquitous in the environment, while their roles are still uncertain due to the limited number of cultured species (Lucheta et al. 2013). In this study, a considerable proportion of Chloroflexi organisms (5-24\%) was found in the FWSF-CW, usually higher than the reported values in other $\mathrm{CW}$ systems used for surface water treatment (Ligi et al. 2014; Guan et al. 2015; Long et al. 2016a, b; Cao et al. 2017). Chloroflexi proportion in VF-CWs used for surface water treatment could vary considerably among both layer depths and sampling times (Guan et al. 2015; He et al. 2016). The present study further displayed a remarkable change of Chloroflexi proportion with season and sampling site in a FWSF-CW used for river water treatment. Moreover, Chloroflexi proportion was found to have a link with wetland vegetation type. To date, information on the environmental variables driving Chloroflexi proportion in FWSF-CW used for surface water treatment is still lacking. In this study, no clear correlation of Chloroflexi proportion with wetland environmental variables was identified.

\section{Conclusions}

Bacterial community abundance, richness, diversity, and composition in the FWSF-CW used for river water treatment could considerably vary among both seasons and sampling sites. Wetland bacterial community might be influenced by vegetation type and a number of environmental variables (especially trophic status). Bacterial community was mainly composed of Proteobacteria and Chloroflexi.

Funding This work was financially supported by National Basic Research Program of China (No. 2015CB458900).

\section{Compliance with ethical standards}

Conflict of interest The authors declare that they have no competing interests.

Research involving human participants and/or animals This article does not contain any studies with human participants or animals performed by any of the authors.

Informed consent Not applicable.

Publisher's note Springer Nature remains neutral with regard to jurisdictional claims in published maps and institutional affiliations.

\section{References}

Arroyo P, Ansola G, deMieraL ES (2013) Effects of substrate, vegetation and flow on arsenic and zinc removal efficiency and microbial diversity in constructed wetlands. Ecol Eng 51:95-103

Calheiros C, Teixeira A, Pires C, Franco A, Duque A, Crispim L, Moura S, Castro P (2010) Bacterial community dynamics in horizontal flow constructed wetlands with different plants for high salinity industrial wastewater polishing. Water Res 44: 5032-5038

Cao QQ, Wang H, Chen XC, Wang RQ, Liu J (2017) Composition and distribution of microbial communities in natural river wetlands and corresponding constructed wetlands. Ecol Eng 98:40-48

Caporaso JG, Kuczynski J, Stombaugh J, Bittinger K, Bushman FD, Costello EK, Fierer N, Pena AG, Goodrich JK, Gordon JI, Huttley GA, Kelley ST, Knights D, Koenig JE, Ley RE, Lozupone CA, McDonald D, Muegge BD, Pirrung M, Reeder J, Sevinsky JR, Turnbaugh PJ, Walters WA, Widmann J, Yatsunenko T, Zaneveld JKR (2010) QIIME allows analysis of high-throughput community sequencing data. Nat Methods 7:335-336

Chang JJ, Wu SQ, Liang K, Wu ZB, Liang W (2015) Comparative study of microbial community structure in integrated vertical-flow constructed wetlands for treatment of domestic and nitrified wastewaters. Environ Sci Pollut Res 22:3518-3527

Cheng W, Zhang JX, Wang Z, Wang M, Xie SG (2014) Bacterial communities in sediments of a drinking water reservoir. Ann Microbiol 64:875-878 
Dai Y, Yang YY, Wu Z, Feng QY, Xie SG, Liu Y (2016) Spatiotemporal variation of planktonic and sediment bacterial assemblages in two plateau freshwater lakes at different trophic status. Appl Microbiol Biotechnol 100:4161-4175

Dzakpasu M, Wang XC, Zheng YC, Ge Y, Xiong JQ, Zhao YQ (2015) Characteristics of nitrogen and phosphorus removal by a surfaceflow constructed wetland for polluted river water treatment. Water Sci Technol 71:904-912

Edgar RC (2013) UPARSE: highly accurate OTU sequences from microbial amplicon reads. Nat Methods 10:996

Edgar RC, Haas BJ, Clemente JC, Quince C, Knight R (2011) UCHIME improves sensitivity and speed of chimera detection. Bioinformatics 27:2194-2200

Fang T, Bao SP, Sima XF, Jiang H, Zhu WT, Tang W (2016) Study on the application of integrated eco-engineering in purifying eutrophic river waters. Ecol Eng 94:320-328

Guan W, Yin M, He T, Xie SG (2015) Influence of substrate type on microbial community structure in vertical-flow constructed wetland treating polluted river water. Environ Sci Pollut Res 22:1620216209

He T, Guan W, Luan ZY, Xie SG (2016) Spatiotemporal variation of bacterial and archaeal communities in a pilot-scale constructed wetland for surface water treatment. Appl Microbiol Biotechnol 100: 479-1488

Ibekwe AM, Lyon SR, Leddy M, Jacobson-Meyers M (2007) Impact of plant density and microbial composition on water quality from a free water surface constructed wetland. J Appl Microbiol 102:921-936

Jung J, Yeom J, Kim J, Han J, Lim HS, Park H, Hyun S, Park W (2011) Change in gene abundance in the nitrogen biogeochemical cycle with temperature and nitrogen addition in Antarctic soils. Res Microbiol 162:1018-1026

Lee SH, Kang H (2016) The activity and community structure of total bacteria and denitrifying bacteria across soil depths and biological gradients in estuary ecosystem. Appl Microbiol Biotechnol 100: 1999-2010

Lee SH, Kim SY, Ding WX, Kang H (2015) Impact of elevated $\mathrm{CO}_{2}$ and $\mathrm{N}$ addition on bacteria, fungi, and archaea in a marsh ecosystem with various types of plants. Appl Microbiol Biotechnol 99:5295-5305

Li BX, Chen HL, Li NN, Wu Z, Wen ZG, Xie SG, Liu Y (2017) Spatiotemporal shifts in the archaeal community of a constructed wetland treating river water. Sci Total Environ 605-606:269-275

Ligi T, Oopkaup K, Truu M, Preem JK, Nolvak H, Mitsch WJ, Mander U, Truu J (2014) Characterization of bacterial communities in soil and sediment of a created riverine wetland complex using high throughput 16S rRNA amplicon sequencing. Ecol Eng 72:56-66

Liu Y, Zhang JX, Zhao L, Zhang XL, Xie SG (2014) Spatial distribution of bacterial communities in high-altitude freshwater wetland sediment. Limnology 15:249-256

Liu LX, Xu M, Qiu S, Shen RC (2015) Spatial patterns of benthic bacterial communities in a large lake. Int Rev Hydrobiol 100:97-105

Liu JN, Wang JM, Zhao CC, Hay AG, Xie HJ, Zhan J (2016) Triclosan removal in wetlands constructed with different aquatic plants. Appl Microbiol Biotechnol 100:1459-1467

Long Y, Yi H, Chen SL, Zhang ZK, Cui K, Bing YX, Zhuo QF, Li BX, Xie SG, Guo QW (2016a) Influences of plant type on bacterial and archaeal communities in constructed wetland treating polluted river water. Environ Sci Pollut Res 23:19570-19579
Long Y, Zhang ZK, Pan XK, Li BX, Xie SG, Guo QW (2016b) Substrate influences on archaeal and bacterial assemblages in constructed wetland microcosms. Ecol Eng 94:437-442

Lucheta AR, Otero XL, Macias F, Lambais MR (2013) Bacterial and archaeal communities in the acid pit lake sediments of a chalcopyrite mine. Extremophiles 17:941-951

Menon R, Jackson CR, Holland MM (2013) The influence of vegetation on microbial enzyme activity and bacterial community structure in freshwater constructed wetland sediments. Wetlands 33:365-378

Quast C, Pruesse E, Yilmaz P, Gerken J, Schweer T, Yarza P, Peplies J, Glockner FO (2013) The SILVA ribosomal RNA gene database project: improved data processing and web-based tools. Nucleic Acids Res 41:D590-D596

Rietl AJ, Overlander ME, Nyman AJ, Jackson CR (2016) Microbial community composition and extracellular enzyme activities associated with Juncus roemerianus and Spartina alterniflora vegetated sediments in Louisiana Saltmarshes. Microb Ecol 71:290-303

Tu YT, Chiang PC, Yang J, Chen SH, Kao CM (2014) Application of a constructed wetland system for polluted stream remediation. J Hydrol 510:70-78

Wang Z, Yang YY, He T, Xie SG (2015) Change of microbial community structure and functional gene abundance in nonylphenol-degrading sediment. Appl Microbiol Biotechnol 99:3259-3268

Wang Q, Xie HJ, Ngo HH, Guo WS, Zhang J, Liu C, Liang S, Hu Z, Yang ZC, Zhao CC (2016) Microbial abundance and community in subsurface flow constructed wetland microcosms: role of plant presence. Environ Sci Pollut Res 23:4036-4045

Xiong JB, Liu YQ, Lin XG, Zhang HY, Zeng J, Hou JZ, Yang YP, Yao TD, Knight R, Chu HY (2012) Geographic distance and pH drive bacterial distribution in alkaline lake sediments across Tibetan Plateau. Environ Microbiol 14:SI 2457-SI 2466

Xiong W, Xie P, Wang SR, Niu Y, Yang X, Chen WJ (2015) Sources of organic matter affect depth-related microbial community composition in sediments of Lake Erhai, Southwest China. J Limnol 74:310 323

Yu Y, Wang H, Liu J, Wang Q, Shen TL, Guo WH, Wang RQ (2012) Shifts in microbial community function and structure along the successional gradient of coastal wetlands in Yellow River Estuary. Eur J Soil Biol 49:12-21

Yu C, Zhang J, Wu L, Liu YZ, Ge G (2015) Effects of heavy metal and nutrients on benthic microbial communities in freshwater sediment of Poyang Lake (China). J Residuals Sci Technol 12:105-111

Zhang JX, Yang YY, Zhao L, Li YZ, Xie SG, Liu Y (2015a) Distribution of sediment bacterial and archaeal communities in plateau freshwater lakes. Appl Microbiol Biotechnol 99:3291-3302

Zhang J, Wang Q, Fan JL, Xie HJ, Liu C, Liang S, Hu Z, Yang ZC, Zhao CC (2015b) Comparisons of microbial abundance and community among different plant species in constructed wetlands in summer. Ecol Eng 82:376-380

Zheng YC, Wang XCC, Dzakpasu M, Ge Y, Zhao YQ, Xiong JQ (2016) Performance of a pilot demonstration-scale hybrid constructed wetland system for on-site treatment of polluted urban river water in northwestern China. Environ Sci Pollut Res 23:447-454

Zhi EQ, Song YH, Duan L, Yu HB, Peng JF (2015) Spatial distribution and diversity of microbial community in large-scale constructed wetland of the Liao River conservation area. Environ Earth Sci 73: 5085-5094 